\title{
A systematic review and meta-analysis of the effect of resistance exercise therapy on the prognosis of patients after percutaneous coronary intervention
}

\author{
Xiaoying Qiu ${ }^{1 \#}$, Yuelan Qin ${ }^{2 \#}$, Zhaofen Zheng ${ }^{1}$, Lihua $\mathrm{Li}^{1}$, Yan Zhang ${ }^{1}$, Juan Wu ${ }^{1}$, Peiqin $\mathrm{He}^{3}$, Zeya Shi \\ ${ }^{1}$ Department of Cardiovascular Medicine, Hunan Provincial People's Hospital, Changsha, China; ${ }^{2}$ Department of Nursing, Hunan Provincial \\ People's Hospital, Changsha, China; ${ }^{3}$ Department of Pediatrics, Guangdong Women and Children's Hospital, Guangzhou, China; ${ }^{4}$ Department of \\ Nursing Teaching and Research Office, Hunan Provincial People's Hospital, Changsha, China \\ Contributions: (I) Conception and design: X Qiu; (II) Administrative support: Z Shi; (III) Provision of study materials or patients: Y Qin; (IV) \\ Collection and assembly of data: Z Zheng; (V) Data analysis and interpretation: X Qiu; (VI) Manuscript writing: All authors; (VII) Final approval of \\ manuscript: All authors. \\ "These authors contributed equally to this work and should be considered as co-first authors. \\ Correspondence to: Zeya Shi. Department of Nursing Teaching and Research Office, Hunan Provincial People's Hospital, 89 Guhan Road, Furong \\ District, Changsha 410016, China. Email: stone20010326@sina.com.
}

\begin{abstract}
Backgrounda Exercise rehabilitation therapy after percutaneous coronary intervention (PCI) can accelerate physical recovery, improve cardiovascular work efficiency, and reduce the incidence of arterial restenosis. This study aimed to investigate the effect of resistance exercise therapy after PCI by literature search and meta-analysis.

Methods: The databases of Embase, Cochrane library, PubMed, and Ovid were searched for all published English language articles related to resistance exercise after PCI from January 2000 to January 2021. After screening the literature according to the inclusion and exclusion criteria and assessing the risk of bias, RevMan 5.4 software was used to analyze and obtain a forest plot and funnel plot.
\end{abstract}

Results: A total of 7 articles were included in this study for quantitative analysis, involving 776 patients all together. Meta-analysis showed that compared with conventional intervention methods, resistance exercise could reduce the maximum exercise load after PCI [mean difference (MD) $=-25.27,95 \%$ confidence interval (CI): -31.97 to $-18.57, Z=7.39, P<0.00001]$, reduce the peak oxygen consumption of exercise after PCI (MD $=-2.36,95 \% \mathrm{CI}:-3.09$ to $-1.64, \mathrm{Z}=6.42, \mathrm{P}<0.00001)$, increase left ventricular ejection fraction (LVEF; MD $=4.06,95 \% \mathrm{CI}: 0.72$ to $7.40, \mathrm{Z}=2.38, \mathrm{P}=0.02)$, increase the 6 -minute walk distance $(6 \mathrm{MWD} ; \mathrm{MD}=18.23$, $95 \% \mathrm{CI}: 0.22$ to $36.23, \mathrm{Z}=1.98, \mathrm{P}=0.05)$, and improve the quality of life of patients after surgery $(\mathrm{MD}=5.81$, 95\% CI: 1.49 to $10.14, \mathrm{Z}=2.63, \mathrm{P}=0.008)$.

Discussion: Resistance training can improve the physical activity, cardiac function, and quality of life of patients after PCI.

Keywords! Resistance exercise; percutaneous coronary intervention (PCI); rehabilitation effect; meta-analysis

Submitted Sep 30, 2021. Accepted for publication Nov 22, 2021.

doi: 10.21037/apm-21-3048

View this article at: https://dx.doi.org/10.21037/apm-21-3048

\section{Introduction}

Percutaneous coronary intervention (PCI) is a surgery which dredges the stenotic or occluded cardiac coronary artery with interventional techniques, thereby improving myocardial blood perfusion, reconstructing blood supply, relieving myocardial infarction, angina pectoris and other symptoms, and preserving the patient's life (1). After many years of clinical application and development, PCI 
technology has transitioned from early balloon dilatation to the era of metal stents, which can significantly reduce the mortality of coronary heart disease (CHD) and has an irreplaceable position in the cardiovascular field (2). However, PCI technology does not eliminate all risk factors for the disease, and the implantation of cardiac stents can damage vascular endothelial cells, cause thrombosis, cause the coronary artery to develop secondary lesions, and patients may be at risk of coronary restenosis and recurrent myocardial infarction (3). Cardiac rehabilitation (CR) is a series of activities performed to maintain cardiac health. A number of studies have shown that CR activities play an important role in improving cardiac function after PCI, reducing the occurrence of postoperative complications, and reducing the restenosis rate (4). CR involves many components such as medical evaluation, physical activity, drug support, and health education, for which exercise rehabilitation therapy is an important facet. At present, a large number of randomized controlled trials (RCTs) $(5,6)$ have confirmed that exercise rehabilitation therapy after PCI can accelerate physical recovery, improve cardiovascular work efficiency, and reduce the incidence of arterial restenosis; however, most of the studies have focused on regular rehabilitation exercise and the development of healthy living habits for the long run, there have been few studies on the effect of early exercise after PCI. Additionally, the previously applied rehabilitation exercise intervention methods including aerobic exercise, there are still few studies on resistance exercise alone. Therefore, in this study we quantitatively analyzed the effect of early resistance exercise on physical rehabilitation after PCI by means of a meta-analysis.

We present the following article in accordance with the PRISMA reporting checklist (available at https://dx.doi. org/10.21037/apm-21-3048).

\section{Methods}

\section{Database and search strategy}

Embase, Cochrane library, PubMed and Ovid were selected as search database platforms. All published English language articles related to resistance exercise after PCI were searched from January 2000 to January 2021. The search keywords were: Physical training/resistance, exercise/ resistance, and training/stretching/early/Percutaneous coronary intervention/PCI.

\section{Inclusion criteria}

(I) Participants: all patients had undergone PCI, the primary diseases were: CHD, acute myocardial infarction, acute coronary syndrome, acute angina; aged $>18$ years, no mental disorders, no other major organ (liver, kidney) disease; all patients underwent PCI for the first time; (II) intervention measures for the experimental group included using resistance exercise as the main means of rehabilitation (may include aerobic exercise, but only as an adjunct); the control group received conventional intervention, and there may have been other control group interventions (such as taking special devices or methods for postoperative rehabilitation); other nursing measures such as postoperative medication and health education were the same in the 2 groups; (III) at least 1 rehabilitation indicator, availability of complete data, applicable to meta-analysis, rehabilitation indicator data in line with normal distribution, expressed as mean \pm standard deviation.

\section{Exclusion criteria}

(I) Non-primary PCI patients; (II) intervention measures were mainly aerobic exercise, resistance exercise was only used as an assistant; or other exercise devices were used as the main intervention method; intervention frequency and duration were not described in detail; (III) investigation, case analysis, review, guidelines, systematic review of nonRCTs; (IV) rehabilitation indicators missing, or data could not be transformed into users (e.g., data expressed as median).

\section{Literature screening}

After literature screening and retrieval, 2 researchers read the titles and abstracts, manually excluded duplicate studies, obtained the full text of the articles after preliminary screening according to the inclusion and exclusion criteria, and if an article could not be obtained online, contacted the original author to obtain the original full text. The full texts were then read and further screened to obtain the articles for final inclusion in quantitative analysis. In the case of 
conflicting opinion during this process, and failure to reach an agreement after discussion, the third person was invited to arbitrate.

\section{Literature quality evaluation and bias risk assessment}

The Cochrane Reviewer's Handbook (https://training. cochrane.org/handbook) was used to assess the risk of bias in the included studies. The following 6 aspects of evaluation were applied: (I) randomization method; (II) blind method; (III) implementation of allocation concealment; (IV) data integrity; (V) selective reporting bias; (VI) other biases, which were evaluated with 3 types: "low risk", "unclear", and "high risk". If the articles were evaluated as low risk in 6 aspects, it could be judged as Level A; if there were 1 or more "unclear" articles, it could be Level B literatures; if there were 1 or more "high risk" evaluations, it could be categorized as Level C literatures.

\section{Outcome indicators}

Rehabilitation indicators after PCI included: (I) 6-minute walk distance (6MWD); (II) maximum exercise (work) load; (III) muscle strength; (IV) left ventricular end diastolic volume (LVEDV); (V) left ventricular end systolic volume (LVESV); (VI) left ventricular ejection fraction (LVEF); (VII) quality of life (QoL); (VIII) peak oxygen consumption $\left(\mathrm{PVO}_{2}\right)$; (IX) adverse event rate.

\section{Data extraction}

Microsoft Excel was used by 2 researchers to independently extract data after reading the full text of each article, including: author, publication year and month, number of grouped cases, age, gender ratio, intervention measures, intervention frequency, observation time, and rehabilitation indicators. The 2 researchers cross-checked each other's data extraction results and finalized them after discussing any resulting differences.

\section{Statistical analysis}

(I) The software RevMan 5.4 (https://training.cochrane. org/online-learning/core-software-cochrane-reviews/ revman) was used for meta-analysis; (II) inverse variance statistics were used for continuous variables, and mean difference (MD) and 95\% confidence interval (CI) were used to report statistics; (III) forest plot descriptive statistics were used for comparison; (IV) $\mathrm{I}^{2}$ analysis and $\mathrm{Q}$ test were used for literature heterogeneity, $\mathrm{I}^{2}>50 \%$ or $\mathrm{P}<0.1$ was used to indicate heterogeneity of results, random effect model was used to obtain odds ratio (OR) value, otherwise the fixed effects model was used to obtain OR value; $(\mathrm{V})$ heterogeneity investment and sensitivity analysis: if heterogeneity between studies was suggested, the heterogeneity source could not be judged, a case-bycase exclusion method was used to investigate the source of heterogeneity, and sensitivity analysis was performed by comparing random effect results and fixed effect results; (VI) a Funnel plot was used to express publication bias.

\section{Results}

\section{Literature screening results}

The literature selection flow chart is displayed in Figure 1. Finally, 7 articles were included in the quantitative analysis, with a total of 776 participants. The basic characteristics, intervention measures, and rehabilitation indicators of all literatures are shown in Table 1.

\section{Literature quality and bias evaluation}

In this study, all articles described the generation method of random sequence (permuted block randomization method or computer random sequence generation method), described the allocation concealment method (sealed opaque envelope concealment number), described the implementation blind method, recorded the dropout cases in detail, were without obvious selective reporting bias and other biases, and the overall quality was excellent, as shown in Table 2.

\section{Meta-analysis results}

\section{Effect of resistance exercise on post-PCI mobility (motor ability) Maximum exercise load}

A total of 4 articles (7-10) reported the maximum exercise load (max. work load) index after intervention, without statistical heterogeneity in the studies $\left(\mathrm{I}^{2}=41 \%, \mathrm{P}=0.17\right)$. Using the fixed effects model, meta-analysis statistics revealed that resistance exercise could reduce the maximum exercise load after PCI (MD $=-25.27,95 \%$ CI: -31.97 to $-18.57, Z=7.39, \mathrm{P}<0.00001)$, as shown in Figure 2. 


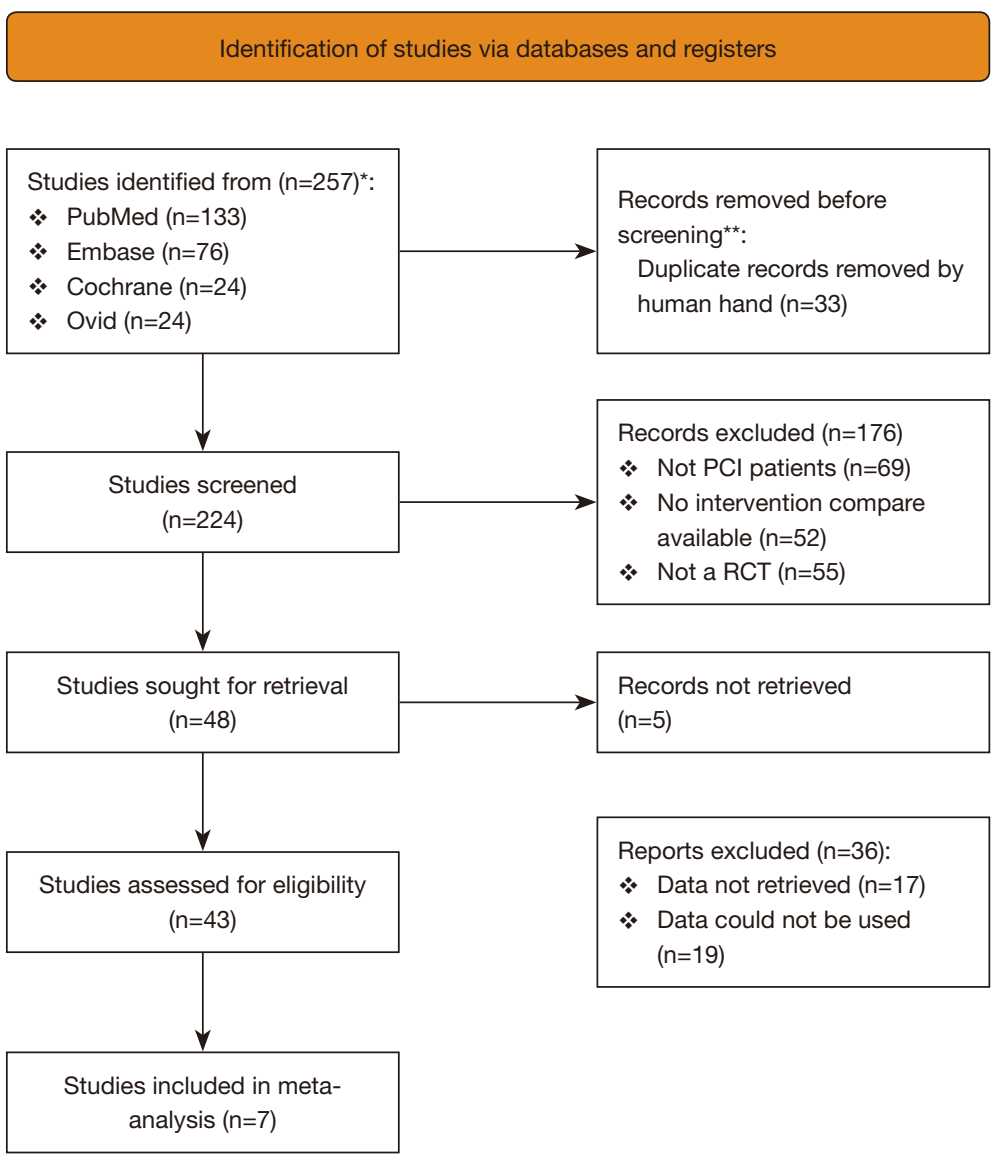

Figure 1 Literature selection flow chart.

\section{$\mathrm{PVO}_{2}$}

A total of 5 articles $(8-11,13)$ reported the $\mathrm{PVO}_{2}$ index after intervention, without statistical heterogeneity in the studies $\left(\mathrm{I}^{2}=19 \%, \mathrm{P}=0.29\right)$. Using the fixed effects model, the resistance exercise obtained by meta-analysis statistics could reduce the $\mathrm{PVO}_{2}$ of exercise after PCI [MD $=-2.36,95 \%$ CI: -3.09 to -1.64$), Z=6.42, \mathrm{P}<0.00001$ ], as shown in Figure 3.

\section{Effect of resistance exercise on cardiac function after PCI LVEF}

A total of 3 articles (7-9) reported LVEF index after intervention, without statistical heterogeneity in the studies $\left(\mathrm{I}^{2}=38 \%, \mathrm{P}=0.20\right)$. Using the fixed effects model, metaanalysis showed that resistance exercise could increase LVEF ( $M D=4.06,95 \%$ CI: 0.72 to $7.40, Z=2.38, P=0.02$ ), as shown in Figure 4.

\section{Effect of resistance exercise on 6MWD after PCI 6MWD}

Four articles $(8-10,12)$ reported $6 \mathrm{MWD}$ statistics, and the studies showed statistical homogeneity $\left(\mathrm{I}^{2}=0 \%, \mathrm{P}=0.50\right)$. Using the fixed effects model, meta-analysis showed that resistance exercise could increase 6MWD $(\mathrm{MD}=18.23$, $95 \%$ CI: 0.22 to $36.23, Z=1.98, P=0.05$ ), as shown in Figure 5.

\section{QoL}

Four articles $(7,9,12,13)$ reported the QoL after the intervention, and the studies showed statistical heterogeneity $\left(\mathrm{I}^{2}=82 \%, \mathrm{P}=0.0007\right)$. Using the random effects model, meta-analysis statistics showed that resistance exercise could improve the QoL of patients after the operation (MD $=5.81,95 \%$ CI: 1.49 to $10.14, Z=2.63, P=0.008$ ), as shown in Figure 6. 
Table 1 Basic characteristics, intervention measures, and rehabilitation indicators of included articles

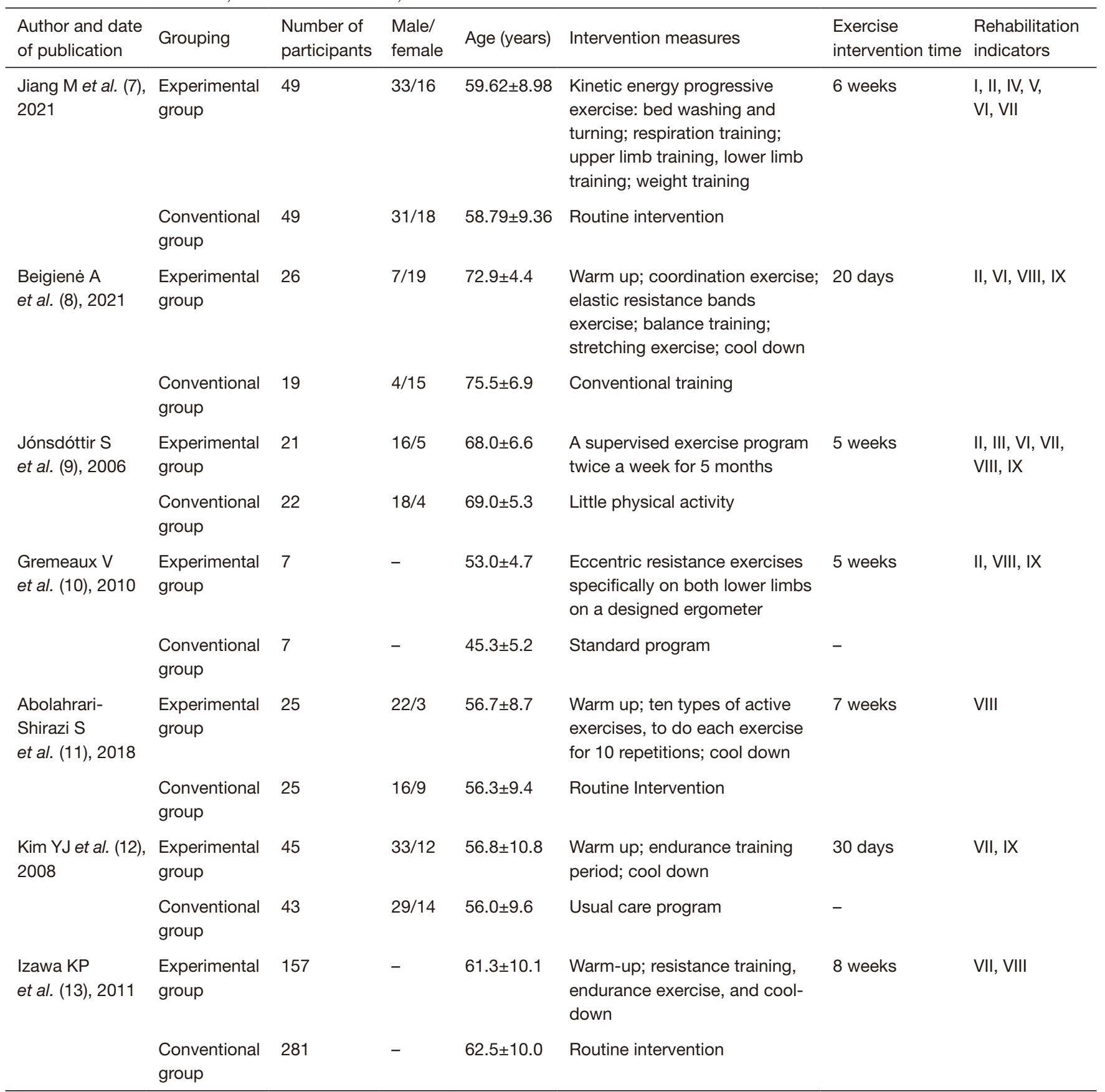

Rehabilitation indicators: (I) adverse events rate; (II) maximum exercise (work) load; (III) muscle strength; (IV) LVEDV; (V) LVESV; (VI) LVEF; (VII) QoL; (VIII) peak oxygen consumption, PVO2; (IX) 6MWD. LVEDV, left ventricular end diastolic volume; LVESV, left ventricular end systolic volume; LVEF, left ventricular ejection fraction; 6MWD, 6-minute walking distance.

\section{Adverse events rate}

Only 1 article (7) reported the adverse reactions during the intervention. The adverse reactions caused by exercise mainly included muscle soreness, myocardial chest distress, dizziness, and shortness of breath. The adverse reaction rate caused by resistance exercise was lower than that of general exercise intervention measures $(2.04 \%$ vs. $16.03 \%$, $\mathrm{P}=0.036$ ). 
Table 2 Risk of bias and quality assessment based on the Cochrane Handbook for Evaluation of Randomized Interventions

\begin{tabular}{|c|c|c|c|c|c|c|c|}
\hline Study & $\begin{array}{l}\text { Random sequence } \\
\text { generation }\end{array}$ & $\begin{array}{l}\text { Classification } \\
\text { hiding }\end{array}$ & $\begin{array}{l}\text { Blind } \\
\text { method }\end{array}$ & $\begin{array}{l}\text { Data } \\
\text { integrity }\end{array}$ & $\begin{array}{l}\text { Optional } \\
\text { reporting }\end{array}$ & Other bias & Grade \\
\hline Jiang M et al. (7), 2021 & Low & Low & Low & Low & Low & Low & Class A \\
\hline Jónsdóttir S et al. (9), 2006 & Low & Low & Low & Low & Low & Low & Class A \\
\hline Kim YJ et al. (12), 2008 & Low & Low & Low & Low & Low & Low & Class A \\
\hline Izawa KP et al. (13), 2011 & Low & Low & Low & Low & Low & Low & Class A \\
\hline
\end{tabular}

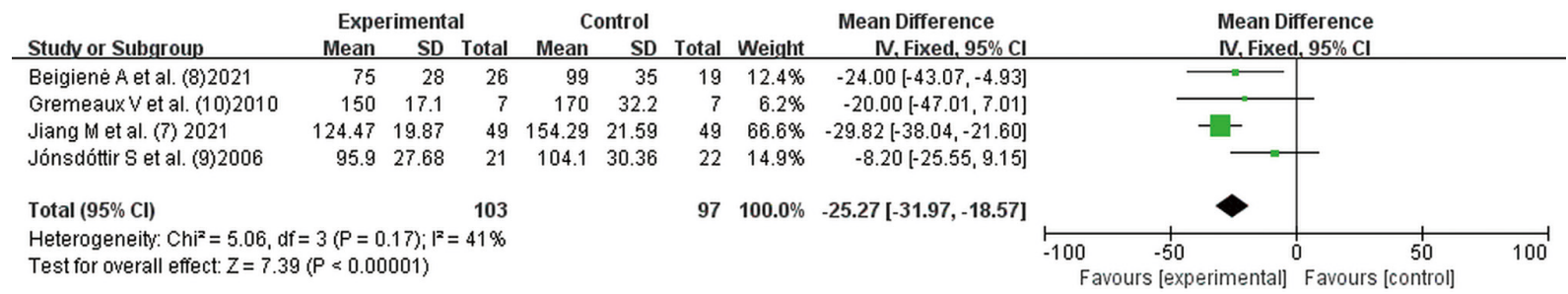

Figure 2 Effect of resistance exercise intervention on postoperative maximum exercise load in patients undergoing PCI (7-10). CI, confidence interval; PCI, percutaneous coronary intervention; SD, standard deviation.

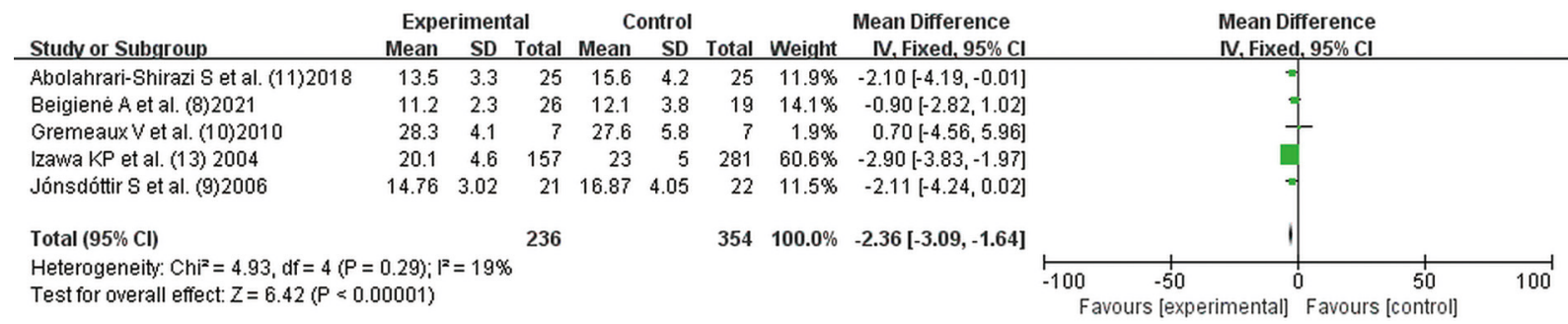

Figure 3 Effect of resistance exercise intervention on postoperative peak oxygen consumption $\mathrm{PVO}_{2}$ in patients undergoing PCI $(8-11,13)$. $\mathrm{CI}$, confidence interval; $\mathrm{PCI}$, percutaneous coronary intervention; $\mathrm{PVO}_{2}$, peak oxygen consumption; SD, standard deviation.

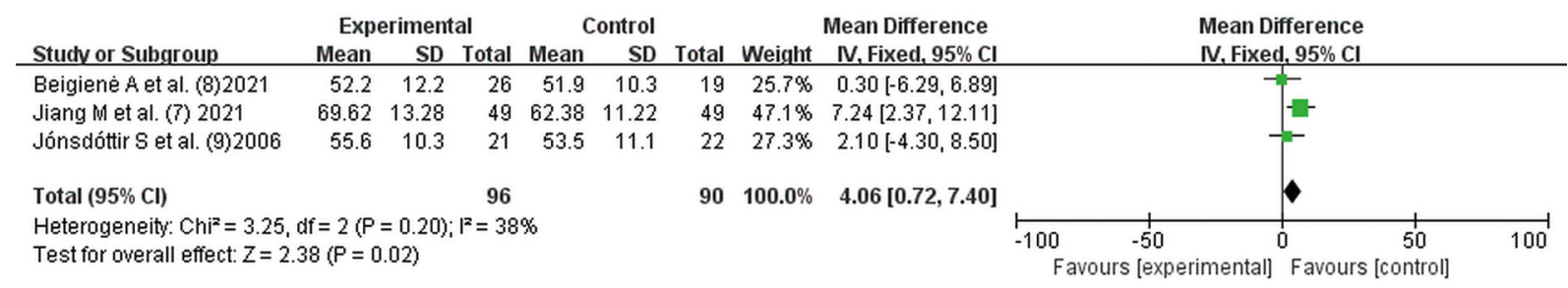

Figure 4 Effect of resistance exercise intervention on LVEF after PCI (7-9). CI, confidence interval; LVEF, left ventricular ejection fraction; PCI, percutaneous coronary intervention; SD, standard deviation. 


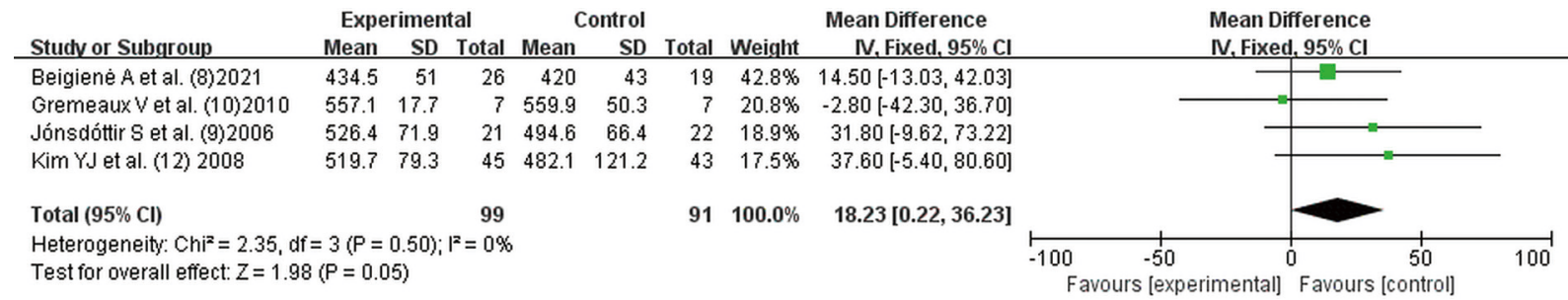

Figure 5 Effect of resistance exercise intervention on postoperative walking distance in patients undergoing PCI surgery (8-10,12). CI, confidence interval; PCI, percutaneous coronary intervention; SD, standard deviation.

\begin{tabular}{|c|c|c|c|c|c|c|c|c|c|c|c|c|c|}
\hline \multirow[b]{2}{*}{ Studv or Subgroup } & \multicolumn{3}{|c|}{ Experimental } & \multicolumn{2}{|c|}{ Control } & \multirow[b]{2}{*}{ Total } & \multirow{2}{*}{\multicolumn{2}{|c|}{$\begin{array}{cl} & \text { Mean Difference } \\
\text { Weight } & \text { IV, Random, } 95 \% \mathrm{Cl} \\
\end{array}$}} & \multirow{2}{*}{\multicolumn{5}{|c|}{$\begin{array}{l}\text { Mean Difference } \\
\text { IV, Random, } 95 \% \mathrm{Cl}\end{array}$}} \\
\hline & Mean & SD & Total & Mean & SD & & & & & & & & \\
\hline Kim YJ et al. (12) 2008 & 61 & 6 & 45 & 52 & 10 & 43 & $26.5 \%$ & $9.00[5.53,12.47]$ & & & 불 & & \\
\hline Jónsdóttir $S$ et al. (9)2006 & 47.55 & 8.7 & 21 & 44.1 & 14.04 & 22 & $17.5 \%$ & $3.45[-3.50,10.40]$ & & & - & & \\
\hline Jiang M et al. (7) 2021 & 89.26 & 8.41 & 49 & 80.53 & 7.36 & 49 & $27.4 \%$ & $8.73[5.60,11.86]$ & & & $=$ & & \\
\hline Izawa KP et al. (13) 2004 & 99.3 & 13.6 & 157 & 97.8 & 13.9 & 281 & $28.5 \%$ & $1.50[-1.18,4.18]$ & & & 亘 & & \\
\hline Total $(95 \% \mathrm{Cl})$ & & & 272 & & & 395 & $100.0 \%$ & $5.81[1.49,10.14]$ & & & & & \\
\hline \multicolumn{7}{|c|}{$\begin{array}{l}\text { Heterogeneity: } \text { Tau }^{2}=15.23 ; \mathrm{Chi}^{2}=16.92, \mathrm{df}=3(\mathrm{P}=0.0007) ; \mathrm{I}^{2}=82 \% \\
\text { Test for overall effect: } Z=2.63(\mathrm{P}=0.008)\end{array}$} & & & -100 & $\begin{array}{l}-50 \\
-5 \text { [exp }\end{array}$ & ${ }^{0}$ & 50 & 100 \\
\hline
\end{tabular}

Figure 6 Effect of resistance exercise intervention on postoperative quality of life in patients undergoing PCI (7,9,12,13). CI, confidence interval; PCI, percutaneous coronary intervention; SD, standard deviation.

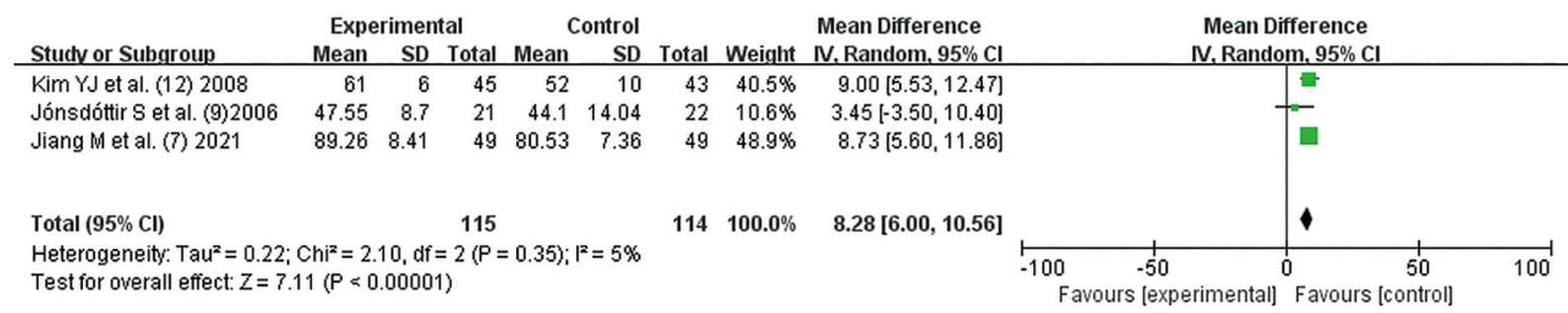

Figure 7 Heterogeneity survey and sensitivity analysis $(7,9,12)$. CI, confidence interval; SD, standard deviation.

\section{Source of heterogeneity and sensitivity analysis}

As only 4 articles with QoL assessment had significant heterogeneity, the case-by-case exclusion method was used. After excluding the article (13), there was no statistical heterogeneity among the remaining 3 studies $\left(\mathrm{I}^{2}=5 \%\right.$, $\mathrm{P}=0.35)$. The difference between the analysis of article 13 and other studies was that the health-related quality of life (HRQOL) was different, and there was little difference in the results between the random-effects model and the fixedeffects model, indicating that the results had good stability (good sensitivity), as shown in Figure 7.

\section{Analysis of publication bias}

The funnel plot of meta-analysis with the maximum exercise load index showed that the two groups of funnels were not evenly distributed on both sides, suggesting that there may be publication bias, as shown in Figure 8.

\section{Discussion}

In the chronic progressive disease of CHD, coronary atherosclerosis is deposited in the vessel wall due to a variety of causes, which leads to stenosis of the vessel wall and poor blood flow resulting in myocardial ischemia and hypoxia, leading to the emergency events such as myocardial infarction and acute angina pectoris (14). Surgical PCI is still an important treatment for CHD, and exercise rehabilitation is the main rehabilitation strategy after PCI surgery followed by drug therapy. It has been pointed out (15) that cardiovascular morbidity and mortality are closely 


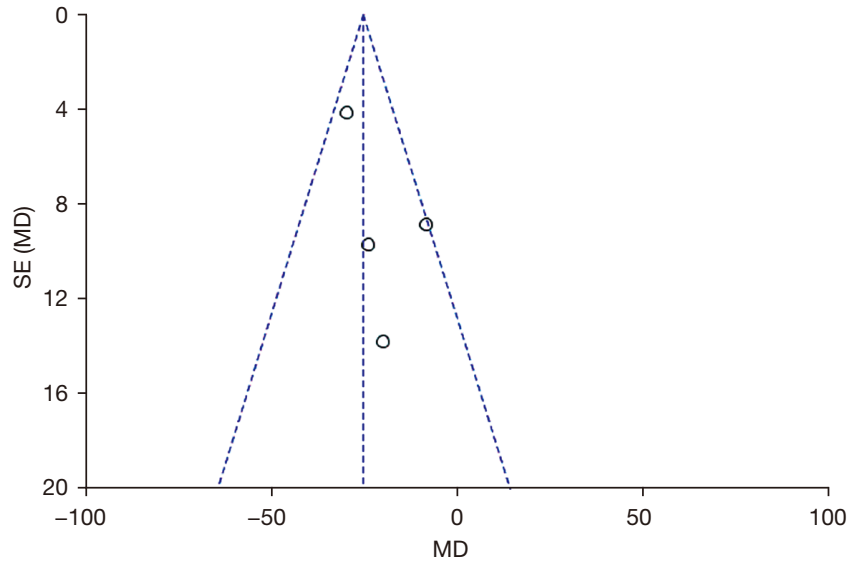

Figure 8 Funnel plot of the effect of resistance exercise intervention on postoperative maximum exercise load in patients undergoing PCI. MD, mean difference; SE, standard error; PCI, percutaneous coronary intervention.

related to whether individuals exercise. In a meta-analysis conducted by Zhang et al. (16), 10 RCTs with a total of 1,274 patients were included. The results showed that physical rehabilitation training after PCI can significantly reduce cardiovascular mortality, reduce the incidence of angina and restenosis, and improve the left ventricular score. However, these RCTs mainly focused on aerobic exercise. The meta-analysis by Yamamoto et al. (17) included 22 RCTs in which aerobic exercise was combined with resistance exercise and compared with the intervention of aerobic exercise alone, and the results showed that resistance training could improve the exercise ability and muscle strength of middle-aged and elderly patients with CHD and improve the capacity for activity among elderly patients. However, their study focused on the long-term benefits of resistance training for elderly patients with CHD, whereas our study has focused on early rehabilitation effects of resistance training for patients after PCI. There were a total of 7 studies included, with a sum of 776 patients undergoing PCI. The results showed that resistance training after surgery could improve the activity ability of patients after surgery, improve cardiac function, and improve the QoL after surgery.

Rehabilitation physiotherapists usually focus on suggestions for daily life after the disease. Rehabilitation training is mainly based on aerobic training, such as walking, walking up and down stairs, and bicycle training, with little attention given to resistance training (18). In fact, after a PCI procedure for myocardial infarction, patients usually require 4-6 weeks of bed rest, and without any intervention, they will face decreased cardiopulmonary function, strength, and flexibility (19). Resistance exercises can benefit patients in the following aspects: (I) increase their muscle strength necessary for daily life; (II) ameliorate fatigue and inertia, reduce depression, and improve selfefficacy (20); (III) reduce hypoglycemia and insulin levels, reduce resting blood pressure, and reduce risk factors for cardiovascular disease (21).

There is no unified guidance on the content of resistance training. In the seven literatures included, the resistance training of patients began during the bed rest after PCI. In literature (7), the intervention mode adopted the kinetic energy progressive movement mode. In the early stage of bed rest, the patients were assisted to wash and turn over in bed, and the patients began the exercise with breathing training and upper limb training. When the patients could get off the bed, the lower limb training and weight-bearing training was added to the program to gradually increase the difficulty. In literature (10), the patients were trained with eccentric resistance on a specially designed dynamometer. In the literature $(8,9,12,13)$, the intervention method includes a group of warm up exercises, followed by limb resistance training, which ends with a group of cool down exercises.

Although resistance training is of great benefit for patients undergoing PCI, its training process still needs to be performed under the guidance of a physiotherapist. In 1 study (7), the possible adverse effects of exercise training on patients were reported, such as muscle aches, palpitations, chest tightness, dizziness, and shortness of breath, and although resistance training has fewer adverse effects than conventional interventions, it still needs to be performed at an intensity and difficulty level that can be tolerated by and most suited to the patient (22).

In this study, the main source of heterogeneity among the articles was inconsistency in the assessment methods used in the studies, for example, in the assessment of QoL, different studies employed different assessment methods, which increased the heterogeneity among studies. The funnel plot showed asymmetry distribution on both sides, which may have been related to over optimistic assessment about the effect of resistance training, and also the small number of included literatures. Therefore, this topic still needs to be deeply investigated through RCTs with adequate sample sizes. 


\section{Conclusions}

A total of 766 patients in 7 studies were included in this meta-analysis. The results showed that the application of resistance training therapy in CR activities after PCI can improve the postoperative physical activity of patients, enhance cardiac function, and improve QoL. Due to the small number of articles included in this study, the subject remains to be further explored via RCTs with adequate sample sizes.

\section{Acknowledgments}

Funding: This work was supported by the 2021 general project supported by Hunan Provincial Health Commission (202114012086) and the Key R \& D projects in the field of social development in Hunan Province (2019sk2021).

\section{Footnote}

Reporting Checklist: The authors have completed the PRISMA reporting checklist. Available at https://dx.doi. org/10.21037/apm-21-3048

Conflicts of Interest: All authors have completed the ICMJE uniform disclosure form (available at https://dx.doi. org/10.21037/apm-21-3048). The authors have no conflicts of interest to declare.

Ethical Statement: The authors are accountable for all aspects of the work in ensuring that questions related to the accuracy or integrity of any part of the work are appropriately investigated and resolved.

Open Access Statement: This is an Open Access article distributed in accordance with the Creative Commons Attribution-NonCommercial-NoDerivs 4.0 International License (CC BY-NC-ND 4.0), which permits the noncommercial replication and distribution of the article with the strict proviso that no changes or edits are made and the original work is properly cited (including links to both the formal publication through the relevant DOI and the license). See: https://creativecommons.org/licenses/by-nc-nd/4.0/.

\section{References}

1. Main A, Saw J. Percutaneous Coronary Intervention for the Treatment of Spontaneous Coronary Artery
Dissection. Interv Cardiol Clin 2019;8:199-208.

2. Throndson K, Sawatzky JA. Improving outcomes following elective percutaneous coronary intervention: the key role of exercise and the advanced practice nurse. Can J Cardiovasc Nurs 2009;19:17-24.

3. Xue L, Guo D, Wang L, et al. Objectifying the level of incomplete revascularization by residual SYNTAX score and evaluating the impact of incomplete revascularization on exercise tolerance in patients with coronary atherosclerotic heart disease treated by percutaneous coronary intervention. Medicine (Baltimore) 2020;99:e22221.

4. Stergiopoulos K, Boden WE, Hartigan P, et al. Percutaneous coronary intervention outcomes in patients with stable obstructive coronary artery disease and myocardial ischemia: a collaborative meta-analysis of contemporary randomized clinical trials. JAMA Intern Med 2014;174:232-40.

5. Fu C, Wang H, Wei Q, et al. Effects of rehabilitation exercise on coronary artery after percutaneous coronary intervention in patients with coronary heart disease: a systematic review and meta-analysis. Disabil Rehabil 2019;41:2881-7.

6. Yang X, Li Y, Ren X, et al. Effects of exercise-based cardiac rehabilitation in patients after percutaneous coronary intervention: A meta-analysis of randomized controlled trials. Sci Rep 2017;7:44789.

7. Jiang $M$, Hua $M$, Zhang $X$, et al. Effect analysis of kinetic energy progressive exercise in patients with acute myocardial infarction after percutaneous coronary intervention: a randomized trial. Ann Palliat Med 2021;10:7823-31.

8. Beigienė A, Petruševičienè D, Barasaitè $\mathrm{V}$, et al. Cardiac Rehabilitation and Complementary Physical Training in Elderly Patients after Acute Coronary Syndrome: A Pilot Study. Medicina (Kaunas) 2021;57:529.

9. Jónsdóttir S, Andersen KK, Sigurosson AF, et al. The effect of physical training in chronic heart failure. Eur J Heart Fail 2006;8:97-101.

10. Gremeaux V, Duclay J, Deley G, et al. Does eccentric endurance training improve walking capacity in patients with coronary artery disease? A randomized controlled pilot study. Clin Rehabil 2010;24:590-9.

11. Abolahrari-Shirazi S, Kojuri J, Bagheri Z, et al. Efficacy of combined endurance-resistance training versus endurance training in patients with heart failure after percutaneous coronary intervention: A randomized controlled trial. J Res Med Sci 2018;23:12. 
12. Kim YJ, Shin YO, Bae JS, et al. Beneficial effects of cardiac rehabilitation and exercise after percutaneous coronary intervention on hsCRP and inflammatory cytokines in CAD patients. Pflugers Arch 2008;455:1081-8.

13. Izawa KP, Watanabe $\mathrm{S}$, Oka $\mathrm{K}$, et al. Cardiac rehabilitation outcome following percutaneous coronary intervention compared to cardiac surgery. Recent Pat Cardiovasc Drug Discov 2011;6:133-9.

14. Kachur S, Chongthammakun V, Lavie CJ, et al. Impact of cardiac rehabilitation and exercise training programs in coronary heart disease. Prog Cardiovasc Dis 2017;60:103-14.

15. Lavie CJ, Arena R, Franklin BA. Cardiac Rehabilitation and Healthy Life-Style Interventions: Rectifying Program Deficiencies to Improve Patient Outcomes. J Am Coll Cardiol 2016;67:13-5.

16. Zhang H, Chang R. Effects of Exercise after Percutaneous Coronary Intervention on Cardiac Function and Cardiovascular Adverse Events in Patients with Coronary Heart Disease: Systematic Review and Meta-Analysis. J Sports Sci Med 2019;18:213-22.

17. Yamamoto S, Hotta K, Ota E, et al. Effects of resistance training on muscle strength, exercise capacity, and mobility in middle-aged and elderly patients with coronary artery

Cite this article as: Qiu X, Qin Y, Zheng Z, Li L, Zhang Y, Wu J, He P, Shi Z. A systematic review and meta-analysis of the effect of resistance exercise therapy on the prognosis of patients after percutaneous coronary intervention. Ann Palliat Med 2021;10(11):11970-11979. doi: 10.21037/apm-21-3048 disease: A meta-analysis. J Cardiol 2016;68:125-34.

18. Adams J, Cline M, Reed M, et al. Importance of resistance training for patients after a cardiac event. Proc (Bayl Univ Med Cent) 2006;19:246-8.

19. Kambic T, Hadžić V, Lainscak M. Hemodynamic Response to High- and Low-Load Resistance Exercise in Patients with Coronary Artery Disease: A Randomized, Crossover Clinical Trial. Int J Environ Res Public Health 2021;18:3905.

20. Beniamini Y, Rubenstein JJ, Zaichkowsky LD, et al. Effects of high-intensity strength training on quality-oflife parameters in cardiac rehabilitation patients. Am J Cardiol 1997;80:841-6.

21. Gjøvaag TF, Mirtaheri P, Simon K, et al. Hemodynamic Responses to Resistance Exercise in Patients with Coronary Artery Disease. Med Sci Sports Exerc 2016;48:581-8.

22. Berent R, von Duvillard SP, Crouse SF, et al. Resistance training dose response in combined endurance-resistance training in patients with cardiovascular disease: a randomized trial. Arch Phys Med Rehabil 2011;92:1527-33.

(English Language Editor: J. Jones) 